\title{
Select Tissue Mineral Concentrations and Chronic Wasting Disease Status in Mule Deer from North-central Colorado
}

Lisa L. Wolfe, ${ }^{1,4}$ Mary M. Conner, ${ }^{2}$ Cathy L. Bedwell, ${ }^{3}$ Paul M. Lukacs, ${ }^{1}$ and Michael W. Miller ${ }^{1}{ }^{1}$ Colorado Division of Wildlife, Wildlife Research Center, 317 West Prospect Road, Fort Collins, Colorado 80526-2097, USA; 2 Department of Wildland Resources, Utah State University, Logan, Utah 84322-5230, USA; ${ }^{3}$ Colorado State University Veterinary Diagnostic Laboratories, Fort Collins, Colorado 80523, USA; ${ }^{4}$ Corresponding author (email: lisa.wolfe@state.co.us)

ABSTRACT: Trace mineral imbalances have been suggested as having a causative or contributory role in chronic wasting disease (CWD), a prion disease of several North American cervid species. To begin exploring relationships between tissue mineral concentrations and CWD in natural systems, we measured liver tissue concentrations of copper, manganese, and molybdenum in samples from 447 apparently healthy, adult ( $\geq 2$ yr old) mule deer (Odocoileus hemionus) culled or vehicle killed from free-ranging populations in northcentral Colorado, United States, where CWD occurs naturally; we also measured copper concentrations in brain-stem (medulla oblongata at the obex) tissue from 181 of these deer. Analyses revealed a wide range of concentrations of all three minerals among sampled deer (copper: 5.6-331 ppm in liver, 1.5-31.9 ppm in obex; manganese: 0.1-21.4 ppm in liver; molybdenum: 0.5-4.0 ppm in liver). Bayesian multiple regression analysis revealed a negative association between obex copper $(-0.097 ; 95 \%$ credible interval -0.192 to -0.006$)$ and the probability of sampled deer also being infected with CWD, as well as a positive association between liver manganese (0.158; $95 \%$ credible interval 0.066 to 0.253 ) and probability of infection. We could not discern whether the tendencies toward lower brain-stem copper concentrations or higher systemic manganese concentrations in infected deer preceded prion infection or rather were the result of infection and its subsequent effects, although the distribution of trace mineral concentrations in infected deer seemed more suggestive of the latter.

Key words: Chronic wasting disease (CWD), copper $(\mathrm{Cu})$, manganese $(\mathrm{Mn})$, molybdenum (Mo), mule deer, Odocoileus hemionus, prion, trace mineral.

Chronic wasting disease (CWD; Williams and Young, 1980) is a transmissible spongiform encephalopathy (TSE) of native North American deer (Odocoileus spp.), elk (Cervus elaphus nelsoni), and moose (Alces alces) that apparently is caused by an aberrant isoform of cellular prion protein (PrP; Williams, 2005). As in TSEs of other ruminant species, CWD infection is characterized by progressive accumulation of disease-associated $\operatorname{PrP}$ $\left(\mathrm{PrP}^{\mathrm{CWD}}\right)$ in a variety of organ systems (Williams, 2005; Fox et al., 2006). Diseaseassociated prion in affected animals presumably arises from conversion of normal cellular $\operatorname{PrP}\left(\operatorname{PrP}^{\mathrm{c}}\right)$ via mechanisms that have not been completely described (Prusiner, 1998).

Understanding of the factors contributing to the rise and persistence of CWD and other prion disease epidemics remains incomplete. Some investigators have suggested that trace mineral imbalancesparticularly those related to copper and similar divalent cations like manganese and molybdenum that can interfere with copper absorption-may cause or contribute to prion disease (Purdey, 2000; Choi et al., 2006; Leach et al., 2007), but unequivocal supporting data are lacking (Zatta and Frank, 2006; Davies and Brown, 2008). Although competitive binding of environmental metals to $\operatorname{PrP}^{\mathrm{c}}$ has been suggested as largely explaining the spatial distribution of CWD and other TSE clusters (Purdey, 2000), concentrations of trace elements in soils on British farms showed no correlation to the incidence of scrapie (Chihota et al., 2004).

Our objective here was to explore relationships between tissue concentrations of select trace minerals and CWD infection status in free-ranging mule deer (Odocoileus hemionus). To this end, we collected sections of fresh liver and brainstem (medulla oblongata at the level of the obex, or "obex" hereafter) tissue from 447 
TABLE 1. Select tissue mineral concentration statistics for chronic wasting disease (CWD) -infected and presumably uninfected, apparently healthy, adult ( $\geq 2 \mathrm{yr}$ old) mule deer sampled in north-central Colorado, USA, 2002-2004.

\begin{tabular}{|c|c|c|c|c|c|c|}
\hline \multirow[b]{3}{*}{ Mineral-tissue } & \multirow[b]{3}{*}{ CWD status } & \multirow[b]{3}{*}{$n$} & \multicolumn{4}{|c|}{ Concentration (parts per million) } \\
\hline & & & \multirow[b]{2}{*}{ Mean } & \multirow[b]{2}{*}{$\mathrm{SE}$} & \multicolumn{2}{|c|}{ Range } \\
\hline & & & & & Lower & Upper \\
\hline \multirow[t]{2}{*}{ Copper-liver } & Uninfected & 357 & 97.9 & 2.9 & 5.6 & 331 \\
\hline & Infected & 89 & 95.7 & 5.8 & 12.2 & 258 \\
\hline \multirow[t]{2}{*}{ Copper-obex } & Uninfected & 139 & 10.3 & 0.5 & 2.9 & 31.9 \\
\hline & Infected & 42 & 8.4 & 0.6 & 1.5 & 18.8 \\
\hline \multirow[t]{2}{*}{ Manganese-liver } & Uninfected & 356 & 8.5 & 0.1 & 0.1 & 21.4 \\
\hline & Infected & 90 & 9.5 & 0.4 & 0.9 & 19.9 \\
\hline \multirow[t]{2}{*}{ Molybdenum-liver } & Uninfected & 292 & 1.9 & 0.03 & 0.5 & 4 \\
\hline & Infected & 73 & 1.8 & 0.1 & 0.6 & 3.1 \\
\hline
\end{tabular}

apparently healthy adult ( $\geq 2$ yr old) mule deer culled or killed in vehicle collisions in north-central Colorado, United States, during 2002-2004. We recorded the sex and the Universal Transverse Mercator coordinates of each deer sampled. Tissues collected for trace mineral analysis were stored frozen at $-70 \mathrm{C}$ until they were prepared for assay.

We measured liver and brain tissue concentrations of copper and liver tissue concentrations of manganese and molybdenum. Our sample included liver tissue from 447 deer, but brain-stem tissue was available from only 181 (Table 1). For analysis, liver and obex tissue samples were air dried under a negative laminar flow hood and then submitted to the Colorado State University Veterinary Diagnostic Laboratory (CSUVDL; Fort Collins, Colorado, USA) for mineral content measurement by atomic absorption spectrophotometry (Association of Official Analytical Chemists, 1990). Trace mineral concentrations were expressed as parts per million (ppm) dry weight of tissue.

To determine the CWD status of each sampled deer, retropharyngeal lymphnode tissue samples were collected and submitted independently to the CSUVDL for detection of $\mathrm{PrP}^{\mathrm{CWD}}$ with the use of an enzyme-linked immunosorbent assay (ELISA) and immunohistochemistry (IHC) by established methods (Miller and Williams, 2002; Hibler et al., 2003). ELISA suspects with presence of $\operatorname{PrP}^{\mathrm{CWD}}$ confirmed by IHC were regarded as CWD infected, and individuals without detectable $\mathrm{PrP} \mathrm{P}^{\mathrm{CWD}}$ by ELISA were regarded as presumably uninfected.

We used Bayesian multiple logistic regression to estimate the effects of each mineral on the probability of an animal being CWD positive. We used normally distributed prior distributions on the regression parameters with mean $=0$ and precision $(1 /$ standard deviation $)=1 \times 10^{-6}$. Our sample included 90 infected (50 female, 40 male) and 357 uninfected (222 female, 135 male) individuals; however, because of sample limitations or occasional assay failures not all individuals were included in all comparisons ( $\mathrm{Ta}-$ ble 1). Missing values for mineral concentrations were imputed from the distribution of the concentration values, which accounted for the uncertainty associated with missing values. We used WinBUGS version 1.4 (Spiegelhalter et al., 2003) to explore the posterior distribution of the model. We generated a Markov chain Monte Carlo (MCMC) chain of 100,000 samples and used the burn-in method to discard the first 50,000 samples. We also estimated means of obex and liver tissue mineral concentrations for CWD-infected and uninfected mule deer (Table 1).

Tissue mineral concentrations in unin- 
A

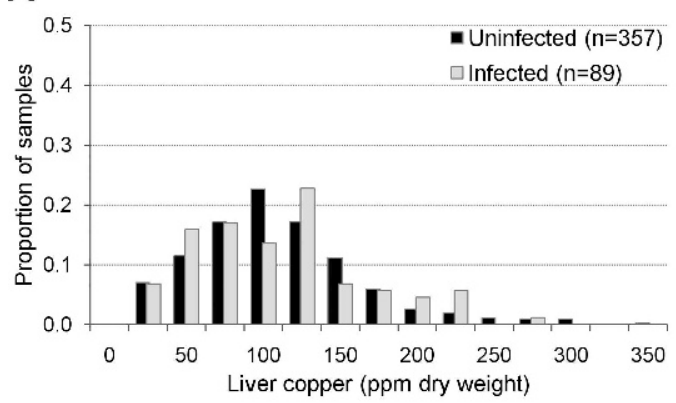

B

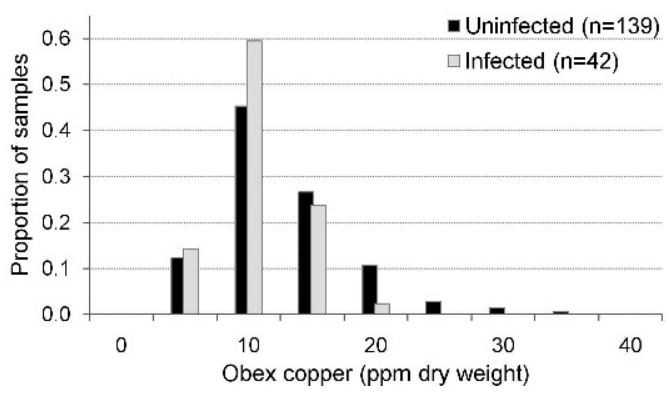

C

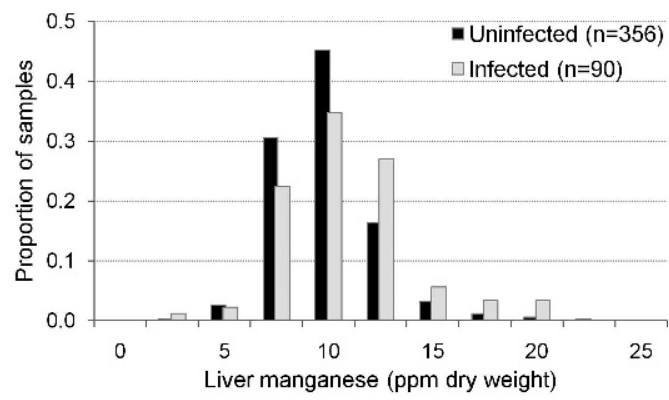

D

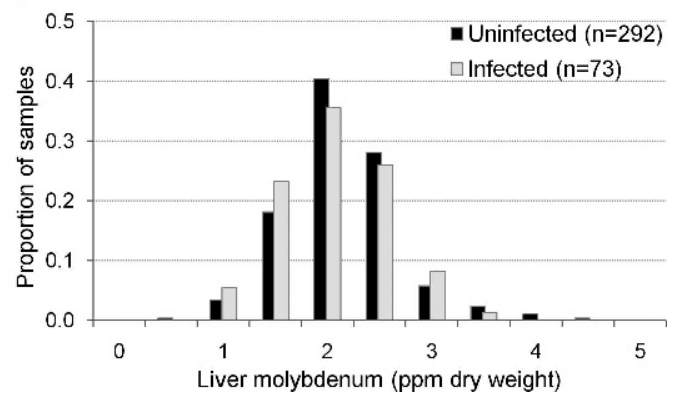

Figure 1. Frequency distribution of (A) liver tissue copper, (B) obex tissue copper, (C) liver tissue manganese, and (D) liver tissue molybdenum concentrations for chronic wasting disease (CWD) -infected and presumably uninfected adult ( $\geq 2$ yr old) mule deer sampled in northern Colorado, USA, 2002-2004. Sample sizes for respective trace mineral analyses are shown in the embedded legend in each panel.

fected mule deer from our study area (Table 1) were similar when compared to values reported elsewhere. Liver copper concentrations averaged $97.9 \mathrm{ppm}$ $(\sigma=54.3, n=357)$ among the mule deer we sampled, similar to the mean concentration (87 ppm, $\sigma=42, n=10$ ) in mule deer reported by Arnhold et al. (1998), but lower than the average (142 ppm converted dry weight, $\mathrm{SE}=13, n=38$ ) reported for adult female mule deer sampled from the southern Black Hills of South Dakota (Zimmerman et al., 2008). Liver molybdenum concentrations in our sample averaged $1.9 \mathrm{ppm}(\sigma=0.54, n=292)$, falling between mean values reported for adult mule deer from the Piceance Basin in northwestern Colorado (1.3 ppm, $\sigma=0.7, n=12$; Stelter, 1980) and the southern Black Hills (3.4 ppm converted dry weight, $\mathrm{SE}=0.1$; Zimmerman et al., 2008). Liver manganese concentrations averaged $8.5 \mathrm{ppm}(\sigma=2.4, n=356)$ among the deer we sampled, compared to $9.4 \mathrm{ppm}$ $(\sigma=2.5, n=29)$ among Montana mule deer (Munshower and Neuman, 1979) and $12.4 \mathrm{ppm}$ (converted dry weight; $\mathrm{SE}=0.4)$ among Black Hills mule deer (Zimmerman et al., 2008).

"Normal" tissue concentrations of copper and other trace mineral concentrations seem to vary widely within and among mule deer populations over both small and large geographic scales. Liver tissue concentrations of copper, manganese, and molybdenum all varied widely among adult mule deer included in our sample (Table 1, Fig. 1), resembling the variation observed in Black Hills mule deer (Zimmerman et al., 2008). Liver copper concentrations in mule deer from Colorado's Piceance Basin averaged $61.4 \mathrm{ppm}(\sigma=34.0)$, but concentrations were twice as high in mule deer sampled just $30 \mathrm{~km}$ to the south (reported in Stelter, 1980). Similarly, mean liver cop- 
TABLE 2. Slope estimates from Bayesian multiple logistic regression analysis of relationships between chronic wasting disease (CWD) infection status (probability of CWD) and tissue mineral concentrations for apparently healthy, adult ( $\geq 2$ yr old) mule deer sampled in north-central Colorado, USA, 2002-2004.

\begin{tabular}{lcrrr}
\hline & & & \multicolumn{2}{c}{$95 \%$ credible interval } \\
\cline { 4 - 4 } & Mean & SD & Lower & Upper \\
\hline Intercept & -0.8896 & 0.7476 & -2.3410 & 0.5816 \\
Sex & -0.3404 & 0.2602 & -0.8525 & 0.1677 \\
Copper (liver) & -0.0020 & 0.0024 & -0.0068 & 0.0026 \\
Copper (obex) & -0.0971 & 0.0478 & -0.1923 & -0.0060 \\
Manganese (liver) & 0.1576 & 0.0474 & 0.0664 & 0.2530 \\
Molybdenum (liver) & -0.3495 & 0.2742 & -0.9092 & 0.1675 \\
\hline
\end{tabular}

per concentrations among "normal" adult female mule deer and white-tailed deer (Odocoileus virginianus) from the southern Black Hills were about three times higher than mean liver copper concentrations among mule deer from Montana (46.3 ppm, $\sigma=29.1, \quad n=29$; Munshower and Neuman, 1979) or white-tailed deer from Texas (54 ppm converted dry weight, $\mathrm{SE}=21$; King et al., 1984).

The overall frequency distributions of liver tissue mineral concentrations in mule deer that we sampled in north-central Colorado were largely similar between CWD-infected and uninfected individuals (Fig. 1). Bayesian multiple regression analysis revealed a negative association between obex copper concentration $(-0.097 ; 95 \%$ credible interval -0.192 to -0.006$)$ and the probability of sampled deer also being infected with CWD, as well as a positive association between liver manganese concentration $(0.158 ; 95 \%$ credible interval 0.066-0.253) and probability of infection (Table 2); infection probability among sampled mule deer did not appear to be influenced by sex or by liver concentrations of copper or molybdenum (Table 2).

If trace mineral deficiencies or excesses were consistently underlying or preceding prion infection in mule deer from our study area, then we would have expected to see a more consistent trend or difference between infected and uninfected individuals in the distribution of one or more of the tissue minerals we measured.
Instead, the overall patterns were remarkably similar between infected and presumably uninfected deer (Fig. 1). Of the three minerals measured in liver tissue, only manganese concentrations showed clear evidence of a relationship with infection probability (Table 2). However, this relationship seemed more suggestive of an effect of prion disease rather than an underlying cause. Infected deer were encountered throughout the range of liver manganese concentrations that we observed (Fig. 1C). Moreover, the relatively small proportion of infected deer with elevated liver manganese concentrations (about 6\% with concentrations $>15$ ppm; Fig. 1C) was comparable to the proportion of infected individuals expected to be in the later stages of infection at any point in time (Miller et al., 2000, Miller and Williams, 2002; Miller et al., 2008). The notion that elevated manganese may be an effect of prion disease in mule deer seems further supported by the relatively high liver manganese concentrations (mean= 13 ppm, SE =3.2, $n=5$ ) measured among clinical CWD cases sampled from this area during the same time period as compared to our sample (Table 1) and to mean concentrations $(9.2 \mathrm{ppm}, \mathrm{SE}=0.8$, $n=9$ ) in other "sick" deer that were not prion infected (L. L. Wolfe, unpubl. data). Circulating manganese increases during the disease course in prion-infected sheep and cattle (Hesketh et al., 2007), and from our data it seems plausible that elevated liver tissue manganese concentrations in 
CWD-infected mule deer also were a consequence of prion infection rather than an underlying cause. Similarly, the negative relationship between the probability of CWD and obex copper concentrations (Table 2) also may have been a consequence of CWD rather than a cause. However, because there was no experimental manipulation in this study we cannot determine with certainty from these data whether the observed differences were a cause or a consequence of CWD.

The lack of evidence for clear causal relationships between CWD infection and tissue mineral concentrations on a local scale also appears consistent with broader geographic patterns of CWD occurrence relative to trace mineral availability. As illustrated above, tissue concentrations of copper, molybdenum, and manganese in North American deer vary widely and appear to have little bearing on either the presence of CWD or its prevalence in endemic areas. For example, CWD has not been detected to date in Montana and Texas and is relatively rare in western Colorado and South Dakota, but given the apparent natural variation in liver copper concentrations across these areas it does not seem surprising that CWD occurrence cannot be predicted by the copper status of resident deer populations. Bush (2000) described trace minerals as "neurochemical factors whose interactions with protein targets induce relations that appear closely relevant to disease pathophysiology." However, the role of trace minerals in chronic wasting disease is still unclear.

Our study was funded by the Colorado Division of Wildlife (CDOW) and the US Department of Agriculture-Animal Plant Health Inspection Service-Veterinary Services. Our analyses included samples gathered through numerous other investigations of CWD in Colorado. We thank I. LeVan, K. Griffin, T. Dubovos, and many, many others at the CDOW Wildlife Health Laboratory for sampling harvested and culled deer over the years, and E.
Williams, P. Jaeger, and others at the University of Wyoming and B. Powers, C. Hibler, T. Spraker, and others at the Colorado State University Veterinary Diagnostic Laboratory for diagnostic support. We also thank D. Clarkson, F. Quartarone, M. Sirochman, and others for collecting field samples. We thank D. Walsh and R. Davies and anonymous referees for helpful reviews of earlier drafts of this manuscript.

\section{LITERATURE CITED}

Association of Official Analytical Chemists. 1990. Official Methods of Analysis of the Association of Official Analytical Chemists. 15th Edition, K. Helrich (ed.). Method No. 974.27, Parts A, B, E and F, and No. 985.40 Part D, Association of Official Analytical Chemists (AOAC), Gaithersburg, Maryland, 1400 pp.

Arnhold, W., M. Anke, M. Glei, B. Rideout, I. Stalis, L. Lowenstine, M. Edwards, K. F. Schüppel, K. Eulenberger, and G. Nötzold. 1998. Determination of copper status in ruminants. Trace Elements and Electrolytes 15: 6569.

Bush, A. I. 2000. Metals and neuroscience. Current Opinion in Chemical Biology 4: 184-191.

Chinota, C. M., M. B. Gravenor, and M. Baylis. 2004. Investigation of trace elements in soil as risk factors in the epidemiology of scrapie. Veterinary Record 154: 809-813.

Choi, C. J., A. Kanthasamy, V. Anantharam, and A. G. Kanthasamy. 2006. Interaction of metals with prion protein: Possible role of divalent cations in the pathogenesis of prion diseases. NeuroToxicology 27: 777-787

Davies, P., and D. R. Brown. 2008. The chemistry of copper binding to PrP: is there sufficient evidence to elucidate a role for copper in protein function? Biochemical Journal 410: 237-244.

Fox, K. A., J. E. Jewell, E. S. Williams, and M. W. Miller. 2006. Patterns of $\operatorname{PrP}^{\mathrm{CWD}}$ accumulation during the course of chronic wasting disease infection in orally inoculated mule deer (Odocoileus hemionus). Journal of General Virology 87: 3451-3461.

Hesketh, S., J. Sassoon, R. Knight, J. Hopkins, and D. R. Brown. 2007. Elevated manganese levels in blood and central nervous system occur before onset of clinical signs in scrapie and bovine spongiform encephalopathy. Journal of Animal Science 85: 1596-1609.

Hibler, C. P., K. L. Wilson, T. R. Spraker, M. W. Miller, R. R. Zink, L. L. DeBuse, E. Andersen, D. Schweitzer, J. A. Kennedy, L. A. Baeten, J. F. Smeltzer, M. D. Salman, and B. E. Powers. 
2003. Field validation and assessment of an enzyme-linked immunosorbent assay for detecting chronic wasting disease in mule deer (Odocoileus hemionus), white-tailed deer (Odocoileus virginianus), and Rocky Mountain elk (Cervus elaphus nelsoni). Journal of Veterinary Diagnostic Investigation 15: 311-319.

King, K. A., J. Leleux, and B. M. Mulhern. 1984. Molybdenum and copper levels in white-tailed deer near uranium mines in Texas. Journal of Wildlife Management 48: 267-270.

Leach, S. P., M. D. Salman, and D. Hamar. 2007. Trace elements and prion diseases: A review of the interactions of copper, manganese and zinc with the prion protein. Animal Health Research Reviews 71: 97-105.

Miller, M. W., and E. S. Williams. 2002. Detecting $\mathrm{PrP}^{\mathrm{CWD}}$ in mule deer by immunohistochemistry of lymphoid tissues. Veterinary Record 151: 610-612.

C. W. McCarty, T. R. Spraker, T. J. Kreeger, C. T. Larsen, and E. T. Thorne. 2000 Epizootiology of chronic wasting disease in freeranging cervids in Colorado and Wyoming. Journal of Wildlife Diseases 36: 676-690.

- H. M. Swanson, L. L. Wolfe, F. G. Quartarone, S. L. Huwer, C. H. Southwick, AND P. M. LuKaCs. 2008. Lions and prions and deer demise. PLoS ONE 3: e4019, doi:10.1371/ journal.pone.0004019.

Munshower, F. F., And D. R. Neuman. 1979. Metals in soft tissues of mule deer and antelope. Bulletin of Environmental Contamination and Toxicology 22: 827-832.
Prusiner, S. B. 1998. Prions. Proceedings of the National Academy of Sciences, USA 95: 1336313383.

Purdey, M. 2000. Ecosystems supporting clusters of sporadic TSEs demonstrate excesses of the radical-generating divalent cation manganese and deficiencies of antioxidant co factors $\mathrm{Cu}$, Se, Fe, Zn Does a foreign cation substitution at prion protein's Cu domain initiate TSE? Medical Hypotheses 54: 278-306.

Spiegelhalter, D., A. Thomas, N. Best, and D. LUnN. 2003. WinBUGS version 1.4. http://www. mrc-bsu.cam.ac.uk/bugs. Accessed April 2010.

Stelter, L. H. 1980. Baseline levels of selected trace elements in Colorado oil shale region animals. Journal of Wildlife Diseases 16: 175-182.

Williams, E. S. 2005. Chronic wasting disease. Veterinary Pathology 42: 530-549.

- AND S. Young. 1980. Chronic wasting disease of captive mule deer: A spongiform encephalopathy. Journal of Wildlife Diseases 16: 89-98.

Zatta, P., and A. Frank. 2006. Copper deficiency and neurological disorders in man and animals. Brain Research Reviews 54: 19-23.

Zimmerman, T. J., J. A. Jenks, D. M. Leslie, Jr., And R. D. Neiger. 2008. Hepatic minerals of whitetailed and mule deer in the southern Black Hills, South Dakota. Journal of Wildlife Diseases 44: 341-350.

Submitted for publication 24 March 2009.

Accepted 25 February 2010. 